\title{
IMP3 is a novel biomarker for adenocarcinoma in situ of the uterine cervix: an immunohistochemical study in comparison with p16 ${ }^{\mathrm{INK} 4 \mathrm{a}}$ expression
}

\author{
Cuizhen Li, Kenneth L Rock, Bruce A Woda, Zhong Jiang, Armando E Fraire and \\ Karen Dresser \\ Department of Pathology, University of Massachusetts Medical School, Worcester, MA, USA
}

\begin{abstract}
Adenocarcinoma in situ of the uterine cervix remains a diagnostic challenge in a small proportion of cases. This suggests a need for biomarker that may be of help in establishing the diagnosis. The aim of this study was to evaluate the potential of insulin-like growth factor-II mRNA-binding protein 3 and cyclin-dependent kinase inhibitor $\mathrm{p} 16^{\mathrm{N} \mathrm{NK} 4 \mathrm{a}}$ as biomarkers for adenocarcinoma in situ. Forty-four samples of adenocarcinoma in situ from 40 patients and 23 control cases of benign uterine cervix were included in this study. In addition to benign endocervical epithelium, 19 of these 23 control cases also showed focal tubal metaplasia. Cytoplasmic immunoreactivity for insulin-like growth factor-II mRNA-binding protein 3 was identified in 41 (93\%) adenocarcinoma in situ samples, among which, $29(71 \%), 10(24 \%)$, and $2(5 \%)$ samples showed insulin-like growth factor-II mRNA-binding protein 3 positive staining in $\mathbf{5 0} \%$ or more, $>\mathbf{5}$ to $<\mathbf{5 0}$ and $<\mathbf{5 \%}$ of adenocarcinoma in situ lesional cells, respectively. Immunohistochemical reaction intensity for insulin-like growth factor-II mRNA-binding protein 3 was found to be strong in 34 adenocarcinoma in situ samples, intermediate in five, and weak in two. All 23 control cases were negative for insulin-like growth factor-II mRNAbinding protein 3. p16 $16^{\mathrm{NK} 4 a}$ expression was identified in all of the adenocarcinoma in situ samples with intermediate staining intensity seen in seven samples and strong in the remainder. Fourteen of $19(74 \%)$ tubal metaplasia cases showed p16 ${ }^{\text {INK } 4 \mathrm{a}}$ immunoreactivity in $>50 \%$ of the tubal metaplastic epithelium with staining intensity ranging from weak to strong. Our findings demonstrate significant expression of insulin-like growth factor-II mRNA-binding protein 3 and p16 ${ }^{\text {INK4a }}$ in adenocarcinoma in situ as compared to benign endocervical glands, suggesting that expression of these biomarkers may be helpful in the distinction of adenocarcinoma in situ from benign endocervical glands, particularly in difficult borderline cases.

Modern Pathology (2007) 20, 242-247. doi:10.1038/modpathol.3800735; published online 22 December 2006
\end{abstract}

Keywords: adenocarcinoma in situ of the uterine cervix; IMP3; p16 ${ }^{\text {INK4a }}$

Adenocarcinoma in situ of the uterine cervix is presently thought to be the precursor lesion of invasive adenocarcinoma, and its incidence is increasing in frequency. ${ }^{1,2}$ The majority of the adenocarcinoma in situ cases are first diagnosed on cervical biopsies, and subsequently confirmed by cold knife cone excision or hysterectomy. Although detailed diagnostic morphologic criteria for adenocarcinoma in situ including nuclear atypia, stratifi-

Correspondence: Dr C Li, MD, PhD, Department of Pathology, Division of Anatomic Pathology, UMass Memorial Medical Center, Three Biotech, One Innovation Drive, Worcester, MA 01605, USA.

E-mail: lic@ummhc.org

Received 26 September 2006; revised 14 November 2006; accepted 16 November 2006; published online 22 December 2006 cation, high mitotic rate, and increased apoptotic bodies $^{1,2}$ have been established, there are a number of cases which present a diagnostic challenge to pathologists in distinguishing adenocarcinoma in situ from benign mimics, such as tubal metaplasia, reactive changes, and other benign processes, particularly in small biopsy samples. At present, ancillary technologies, molecular or immunohistochemical that may aid in making this important distinction are very limited. Here, we present our findings on the role of IMP3 in the diagnosis of adenocarcinoma in situ.

Insulin-like growth factor-II mRNA-binding protein 3 (IMP3) known in previous publications as L523S or KOC ( $K$-homologous domain containing protein overexpressed in cancer), ${ }^{3,4}$ is a newly identified oncofetal RNA-binding protein that binds 
to mRNAs such as insulin-like growth factor-II (IGF-II) transcripts. IMP3 is expressed during embryogenesis but not in most adult tissues. ${ }^{5,6}$ By using cDNA library subtraction and large-scale DNA screening techniques, the IMP3 gene has been found to be expressed in pancreatic and lung carcinomas. $^{7,8}$ The IMP3 protein consists of 580 amino-acid residues and is encoded by a 4350-nucleotide mRNA transcript. The IMP3 gene is located on chromosome 7p11.5. A monoclonal antibody specific for IMP3 has been used successfully with routine immunohistochemical methods to study overexpression of IMP3 protein in a number of malignant tumors. $^{3,4}$ Recently, it has been demonstrated that IMP3 expression is an independent prognostic factor for renal cell carcinoma. ${ }^{9}$

Cyclin-dependent kinase (CDK) inhibitor p16 ${ }^{\mathrm{INK} 4 \mathrm{a}}$ protein is a member of the INK4 family of cell cycle regulatory proteins and specifically inhibits the formation of cyclin D1-CDK4/6 complexes $^{10-12}$ which control the activity of retinoblastoma tumorsuppressor protein $\mathrm{pRb}$ by phosphorylation. ${ }^{13} \mathrm{Re}-$ cent studies have revealed that $\mathrm{p} 16^{\mathrm{INK} 4 \mathrm{a}}$ expression is influenced by the status of $\mathrm{pRb}$ expression by a negative feedback loop between $\mathrm{pRb}$ and $\mathrm{p} 16^{\mathrm{INK} 4 \mathrm{a}}$. Overexpression of $\mathrm{p} 16^{\mathrm{INK} 4 \mathrm{a}}$ has been demonstrated in cervical squamous and glandular neoplasia due to functional inactivation of $\mathrm{pRb}$ by human papillomavirus (HPV) oncoprotein E7. Therefore, p16 $6^{\text {INK4a }}$ is currently considered a biomarker to identify intraepithelial squamous and glandular lesions on both cervical biopsies and cytology specimens.

The primary aim of this study was to evaluate the expression of IMP3 and p16 $6^{\mathrm{INK} 4 \mathrm{a}}$ in adenocarcinoma in situ as well as benign endocervical glands by immunohistochemical techniques with the secondary aim of assessing a possible role of IMP3 in the diagnosis of adenocarcinoma in situ.

\section{Materials and methods}

\section{Case Selection}

Forty consecutive patients with adenocarcinoma in situ of the uterine cervix were identified from the files of the Department of Pathology of the UMass Memorial Medical Center from January 1997 to April 2006. The specimens included six cervical biopsies, 25 cold-knife cone excisions, eight LEEP (loop electrosurgical excision procedure) excisions and five hysterectomies. Four (10\%) of the 40 patients had both their initial biopsy or cone excision and subsequent cone excision or hysterectomy procedures done at UMass Memorial Medical Center, providing a total of 44 samples available for this study. The diagnosis of adenocarcinoma in situ was confirmed according to the published diagnostic $_{\text {criteria. }}{ }^{1,2}$ A control group was derived from 23 patients who underwent hysterectomy at UMass Memorial Medical Center in 2004 for benign uterine lesions including leiomyomas, adenomyo- sis, and endometrial polyps. All 23 control patients showed normal endocervical glandular epithelium. Focal tubal metaplasia in the endocervix was identified in 19 of the 23 control cases. No squamous intraepithelial lesions or other endocervical glandular abnormalities were found among these 23 patients.

\section{Immunohistochemical Study}

Immunohistochemical stains were performed as described previously. ${ }^{4,9}$ Briefly, $5-\mu \mathrm{m}$ tissue sections from selected blocks were cut, deparaffinized, washed, immersed in citrate buffer $(0.01 \mathrm{M}, \mathrm{pH}$ 6.0 ), and underwent microwave $(770 \mathrm{~W}, 14 \mathrm{~min})$ antigen retrieval. The slides were cooled, rinsed with PBS (three rinses, 5 min each), and stained on a DAKO Autostainer (DAKO Corporation, Carpinteria, CA, USA) at room temperature. Endogenous peroxidase activity was blocked with $3 \%$ hydrogen peroxide, and the slides were rinsed and treated with a blocking protein (Chemmate, Ventana, and Tuscon, AZ, USA) to prevent non-specific staining. The sections were then incubated with L523S, a mouse monoclonal antibody specific for IMP3 $(2 \mu \mathrm{g} / \mathrm{ml}$; Corixa Corporation, Seattle, WA, USA) for $45 \mathrm{~min}$, or with p16 ${ }^{\mathrm{INK} 4 \mathrm{a}}$ mouse monoclonal antibody (clone: 6H12; dilution: 1:100; Novocastra Laboratories, UK) for $30 \mathrm{~min}$. Following brief buffer washes, the sections were treated with a cocktail of biotinylated anti-rabbit IgG and anti-mouse IgG/IgM (Chemmate) for $30 \mathrm{~min}$, washed, and incubated with avidin/biotin/peroxidase complex (Chemmate) for $30 \mathrm{~min}$. The sections were rinsed, developed with diaminobenzidine (Chemmate) and hydrogen peroxide $(10 \mathrm{~min})$, rinsed with tap water, and counterstained with hematoxylin.

Representative sections of pancreatic carcinoma were used as positive controls for IMP3 expression and sections of high-grade uterine cervical squamous dysplasia were used as positive control for p16 ${ }^{\text {INK4a }}$. Negative controls were performed by replacing the primary antibody with nonimmune IgG. A positive stain for $\mathrm{p} 16^{\mathrm{INK} 4 \mathrm{a}}$ was defined as brown stain seen in the cytoplasm and/or nucleus. The percentage of adenocarcinoma in situ, tubal metaplasia or normal endocervical glandular epithelium that was positive for either IMP3 or p16 ${ }^{\text {INK4a }}$ was assessed. The intensity of the staining was evaluated as weak, intermediate, or strong.

\section{Results}

\section{Clinicopathologic Features}

The patient age ranged from 23- to 56-year-old, with 16 from 20 to 29,15 from 30 to 39,7 from 40 to 49 , and 2 from 50 to 59 age groups. The mean age was 32 years. Thirteen of 44 specimens had concurrent high-grade squamous intraepithelial lesions. Four 
patients had invasive adenocarcinoma and two had invasive squamous cell carcinoma. The age of the 23 control patients with hysterectomy for benign uterine lesions ranged from 34 to 58 years. All 23 cases had Leiomyomas. Additionally, 13 cases also had adenomyosis, and four had endometrial polyps.
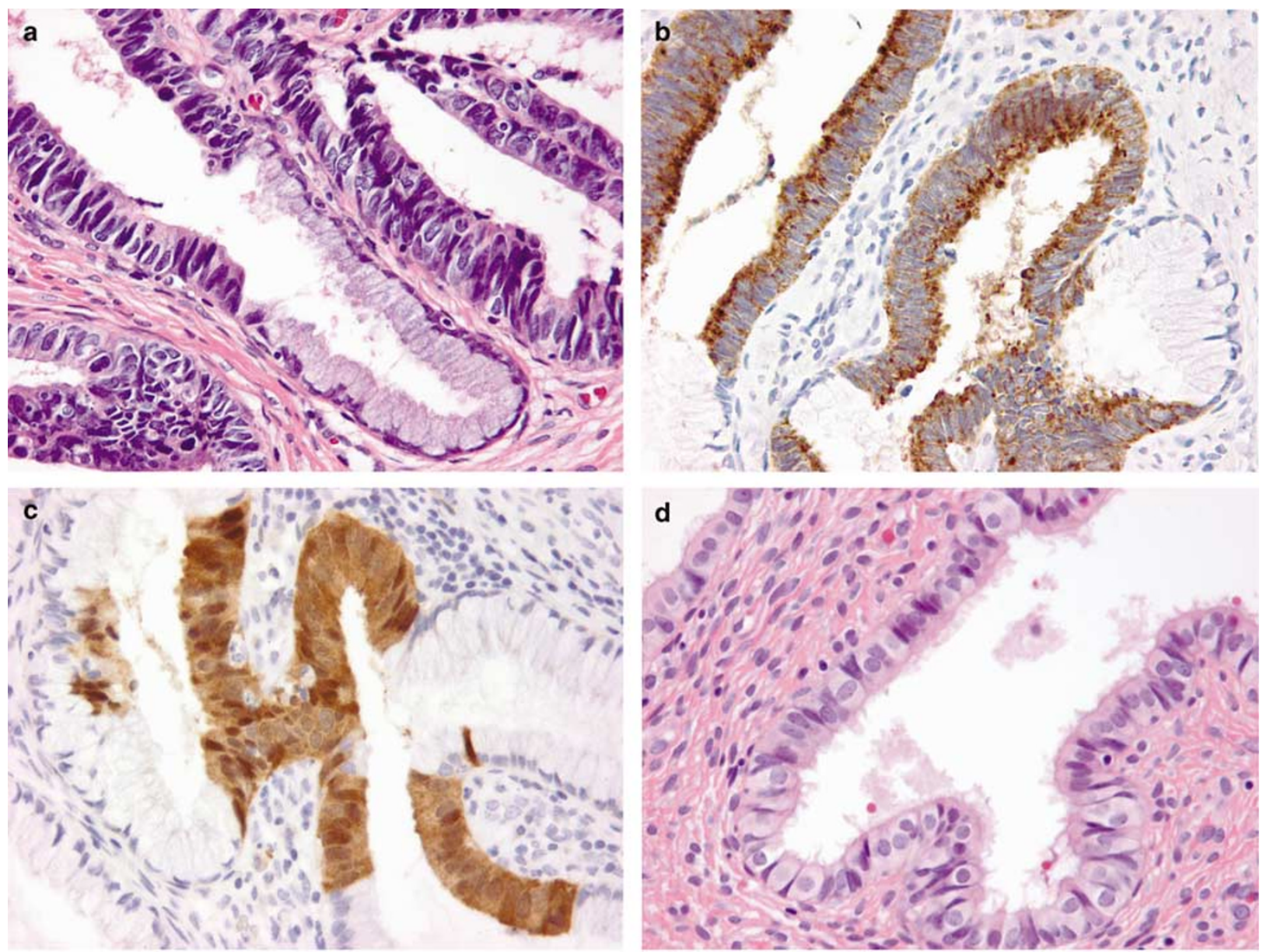

Forty-one of 44 samples with adenocarcinoma in situ (93\%) showed cytoplasmic staining for IMP3 (Figure 1). As indicated in Table 1, among the adenocarcinoma in situ cases, 29 showed positive

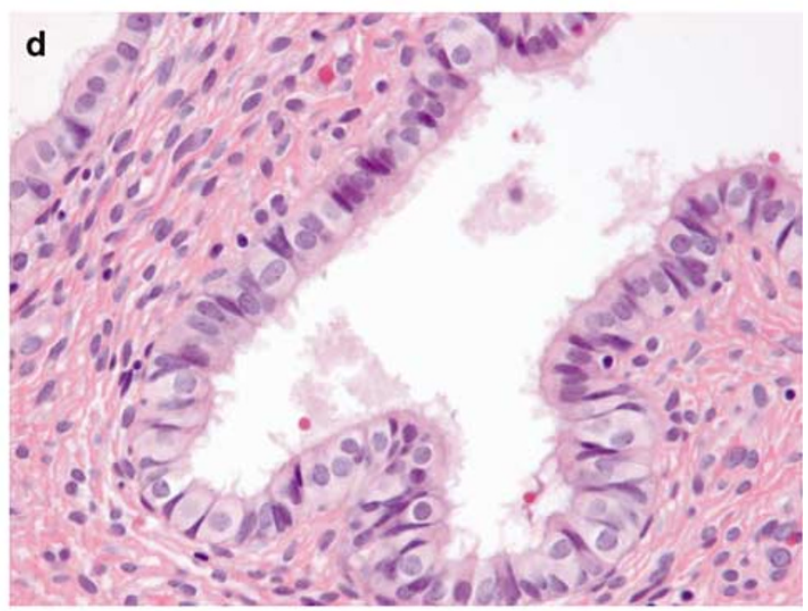

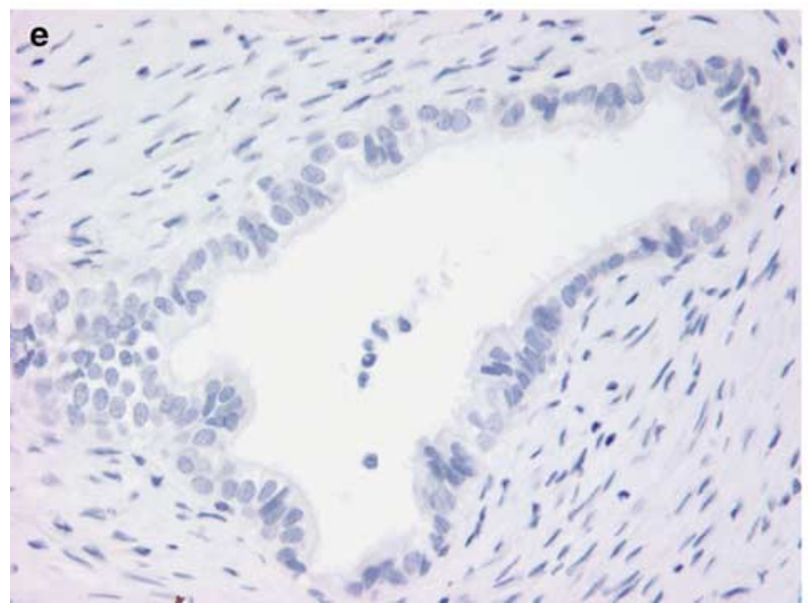

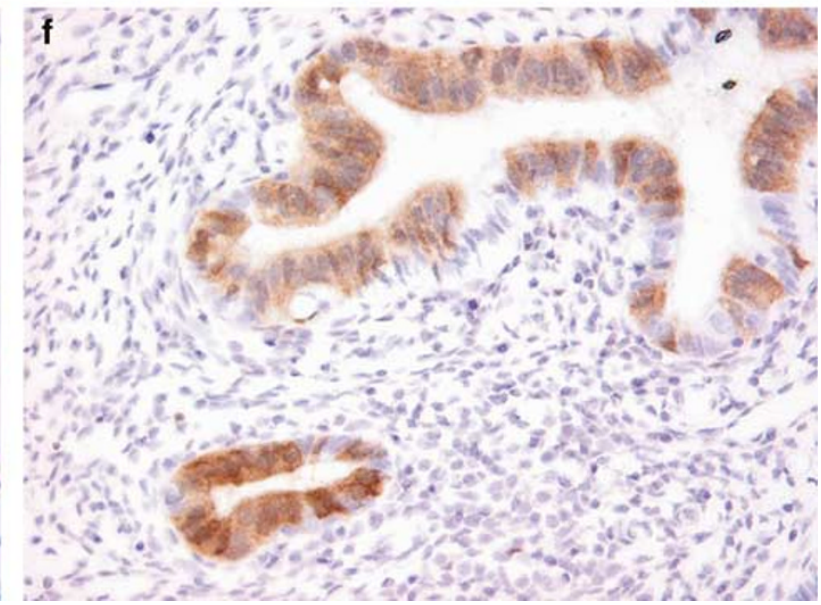

Figure 1 (a) Adenocarcinoma in site of the uterine cervix (H\&E); (b) Strong cytoplasmic expression of IMP3 in adenocarcinoma in site but not in normal endocervical glandular epithelium; (c) Strong cytoplasmic and nuclear expression of p16 ${ }^{\text {INK4a }}$ in adenocarcinoma in site but not in normal endocervical glandular epithelium; (d) Uterine endocervix with tubal metaplasia (H\&E); (e) Negative immunohistochemical stain for IMP3 in tubal metaplasia; (f) Cytoplasmic and nuclear expression of p16 ${ }^{\text {INK4a }}$ in tubal metaplasia. 
Table 1 Expression of IMP3

\begin{tabular}{|c|c|c|c|c|c|c|c|}
\hline \multirow[t]{2}{*}{ Diagnosis } & \multicolumn{3}{|c|}{$\%$ Of positive cells } & \multicolumn{4}{|c|}{ Staining intensity } \\
\hline & 50 or more & $<50$ to $>5$ & $>0$ to 5 & Negative & Strong & Intermediate & Weak \\
\hline AIS $(n=44)$ & $29 / 44$ & $10 / 44$ & $2 / 44$ & $3 / 44$ & $34 / 44$ & $5 / 44$ & $2 / 44$ \\
\hline $\mathrm{TM}(n=19)$ & $0 / 19$ & $0 / 19$ & $0 / 19$ & $19 / 19$ & NA & NA & NA \\
\hline $\operatorname{BEG}(n=23)$ & $0 / 23$ & $0 / 23$ & $0 / 23$ & $23 / 23$ & NA & NA & NA \\
\hline
\end{tabular}

AIS, adenocarcinoma in situ; TM, tubal metaplasia; BEG, benign endocervical glands; NA, not applicable.

Table 2 Expression of $\mathrm{p} 16^{\mathrm{INK} 4 \mathrm{a}}$

\begin{tabular}{|c|c|c|c|c|c|c|c|}
\hline \multirow[t]{2}{*}{ Diagnosis } & \multicolumn{3}{|c|}{$\%$ Of positive cells } & \multicolumn{4}{|c|}{ Staining intensity } \\
\hline & 50 or more & $<50$ to $>5$ & $>0$ to 5 & Negative & Strong & Intermediate & Weak \\
\hline AIS $(n=44)$ & $44 / 44$ & $0 / 44$ & $0 / 44$ & $0 / 44$ & $37 / 44$ & $7 / 44$ & $0 / 44$ \\
\hline $\mathrm{TM}(n=19)$ & $14 / 19$ & $2 / 19$ & $3 / 19$ & $0 / 19$ & $4 / 19$ & $7 / 19$ & $8 / 19$ \\
\hline $\operatorname{BEG}(n=23)$ & $0 / 23$ & $0 / 23$ & $2 / 23$ & $21 / 23$ & $0 / 23$ & $0 / 23$ & $2 / 23$ \\
\hline
\end{tabular}

AIS, adenocarcinoma in situ; TM, tubal metaplasia; BEG, benign endocervical glands.

staining for IMP3 in 50\% or more of cells, 10 cases had staining in $>5$ to $<50 \%$ and two cases were positive in $5 \%$ or less of lesional cells, respectively. IMP3 immunohistochemical reaction intensity was judged to be strong in 34 adenocarcinoma in situ specimens, intermediate in five, and weak in two. The specimens for all three adenocarcinoma in situ cases with negative IMP3 staining were LEEP specimens. Five of 13 concurrent high-grade squamous intraepithelial lesions and two invasive squamous cell carcinoma cases demonstrated significant immunohistochemical expression of IMP3. All of the 23 cases with normal endocervical glandular epithelium and 19 cases of endocervix with tubal metaplasia were negative for IMP3 (Figure 1).

\section{p16 ${ }^{I N K 4 a}$ expression}

Positive immunohistochemical reaction for $\mathrm{p} 16^{\mathrm{INK} 4 \mathrm{a}}$ in adenocarcinoma in situ was characterized by cytoplasmic staining only or positivity seen in both the cytoplasm and nucleus (Figure 1). All of the adenocarcinoma in situ cases showed $\mathrm{p} 16^{\mathrm{INK} 4 \mathrm{a}}$ expression. As shown in Table 2, the staining intensity was intermediate in seven cases, and strong in the remainder. Two out of 23 cases of normal endocervix showed weak $\mathrm{p} 16^{\mathrm{INK} 4 \mathrm{a}}$ staining in $<5 \%$ of the glandular epithelium, and 21 cases were negative. Fourteen out of 19 cases with tubal metaplasia showed both nuclear and cytoplasmic p16 ${ }^{\text {INK4a }}$ positivity in more than $50 \%$ of the tubal metaplastic epithelium, and remaining five cases demonstrated positive $\mathrm{p} 16^{\mathrm{INK} 4 \mathrm{a}}$ stain in $20 \%$ or less of the tubal metaplastic epithelium. Stain intensity for $\mathrm{p} 16^{\mathrm{INK} 4 \mathrm{a}}$ in tubal metaplastic epithelium was strong in four cases, intermediate in seven cases, and weak in eight cases. Thirteen concurrent high- grade squamous intraepithelial lesions and two invasive squamous cell carcinoma cases demonstrated diffuse and strong to intermediate $\mathrm{p} 16^{\mathrm{INK} 4 \mathrm{a}}$ expression.

\section{Discussion}

The IMP3 gene was initially identified in pancreatic carcinomas in $1996,{ }^{7}$ and subsequently cloned in 1997. ${ }^{14}$ IMP3 together with IMP1 and IMP2, three members of human IGF-II mRNA binding protein family were first purified from the human rhabdomyosarcoma cell line RD in $1999 .{ }^{5}$ They have been shown to play an important role in the binding, trafficking, and stabilization of the fetal subtype of IGF-II mRNA during embryogenesis. ${ }^{5,15}$ As a result, IGF-II expression is indirectly regulated by IMP3 and other proteins in the IMP family. IGF-II overexpression has been implicated in the pathogenesis of the tumors in multiple organ systems seen in the Beckwith-Wiedemann syndrome, and the development of breast and liver tumors in transgenic mouse models as well as hepatocellular carcinoma in viral hepatitis mouse models. ${ }^{16-18}$ Therefore, it is hypothesized that IMP family members are involved in carcinogenesis by stabilizing IGF-II mRNA. However, the IMP proteins also bind and affect other mRNAs and this may also influence the malignant potential of cells.

In this study, we have shown that IMP3 is highly expressed in adenocarcinoma in situ of the uterine cervix as compared to benign endocervical glands. Previous data has shown that IMP3 expression is not tumor specific. ${ }^{3,4,9}$ It is more likely that IMP3 is a marker of malignancy. IMP3 overexpression has been reported in carcinomas of the stomach, colon, 
head and neck, liver, and kidney, as well as soft tissue sarcomas. Our studies of gynecologic malignancies have shown that IMP3 is also overexpressed in invasive endocervical adenocarcinomas (data not shown), ovarian carcinomas (data not shown), and endometrial adenocarcinomas, especially serous type. ${ }^{19}$ If IMP3 is a marker of malignancy, then expression of IMP3 in adenocarcinoma in situ as demonstrated in this study provides molecular evidence that adenocarcinoma in situ is malignant and may represent the precursor lesion for invasive cervical adenocarcinoma.

A large body of epidemiologic and molecular data has shown that high-risk types of the human papillomavirus (HPV) are the etiologic agents for most cases of endocervical glandular neoplasia. ${ }^{20}$ HPV virus infection may result in the integration of the HPV genome into the host DNA and the accumulation of HPV oncoprotein E7 which contributes to cellular transformation by interfering with the $\mathrm{p} 16^{\mathrm{INK} 4 \mathrm{a}} / \mathrm{CDK} 4 / \mathrm{cycD} 1 / \mathrm{pRb}$ cell cycle regulatory pathway. Our findings that $\mathrm{p} 16^{\mathrm{INK} 4 \mathrm{a}}$ is overexpressed in all cases of adenocarcinoma in situ are consistent with the previous observation indicating that $\mathrm{p} 16^{\mathrm{INK} 4 \mathrm{a}}$ is a sensitive marker for adenocarcinoma in situ with a sensitivity of $100 \% .{ }^{21,22}$ However, in this study, p16 ${ }^{\mathrm{INK} 4 \mathrm{a}}$ expression was also detected in rare scattered columnar cells in two cases of normal endocervical glands and all specimens exhibiting tubal metaplasia. A previous study by Riethdorf et $a 1^{22}$ also found that $\mathrm{p} 16^{\mathrm{INK} 4 \mathrm{a}}$ was expressed in most cases of tubal metaplasia of the endocervical mucosa. In contrast to $\mathrm{p} 16^{\mathrm{INK} 4 \mathrm{a}}$ we have shown that IMP3 is not expressed in benign endocervical glands or tubal metaplasia indicating that IMP3 shows specificity of $100 \%$ in detecting adenocarcinoma in situ. Three of 44 samples with adenocarcinoma in situ in our study also demonstrated negative staining for IMP3, yielding a sensitivity of $93 \%$ for the identification of adenocarcinoma in situ by IMP3 immunohistochemical staining. Negative staining for IMP3 in these three cases of adenocarcinoma in situ may be caused by the alteration of IMP3 protein during loop electrosurgical excision procedure.

In summary, IMP3 as well as p16 $6^{\mathrm{INK} 4 \mathrm{a}}$ are highly expressed in adenocarcinoma in situ. These findings suggest that, in addition to $\mathrm{p} 16^{\mathrm{INK} 4 \mathrm{a}} \mathrm{IMP} 3$ may prove to be a useful and important biomarker for the diagnosis of adenocarcinoma in situ in equivocal or borderline cases. We have further demonstrated that the IMP3 stain is specific for adenocarcinoma in situ with $100 \%$ specificity, although the sensitivity of this marker was lower than that of $\mathrm{p} 16^{\mathrm{INK} 4 \mathrm{a}}$. However, the use of $\mathrm{p} 16^{\mathrm{INK} 4 \mathrm{a}}$ staining for the diagnosis of adenocarcinoma in situ should be applied with caution due to the findings that focal $\mathrm{p} 16^{\mathrm{INK} 4 \mathrm{a}}$ staining was observed in rare columnar cells of normal endocervical glands and in all of the cases of tubal metaplasia. Although useful as diagnostic aids, IMP3 and p16 ${ }^{\text {INK4a }}$ should be interpreted in conjunction with morphologic examination. The final diagnosis should be rendered on the basis of combined histological criteria and the staining results for these two biomarkers.

\section{Acknowledgements}

We are grateful to the Corixa Corporation for providing the monoclonal antibody against IMP3, and to Mr Louis Savas for his technical support.

\section{References}

1 Zaino R. Glandular lesions of the uterine cervix. Mod Pathol 2000;13:261-274.

2 Ioffe OB, Sagae S, Moritani S, et al. Proposal of a new scoring scheme for the diagnosis of noninvasive endocervical glandular lesions. Am J Surg Pathol 2003;27:452-460.

3 Wang T, Fan L, Watanabe Y, et al. L523S, an RNAbinding protein as a potential therapeutic target for lung cancer. Br J Cancer 2003;88:887-894.

4 Yantiss RK, Woda BA, Fanger GR, et al. KOC (Komology Domain Containing Protein Overexpressed in Cancer): a novel molecular marker that distinguishes between benign and malignant lesions of the pancreas. Am J Surg Pathol 2005;29:188-195.

5 Nielsen J, Christiansen J, Lykke-Andersen J, et al. A family of insulin-like growth factor II mRNA-binding proteins represses translation in late development. Mol Cell Biol 1999;9:1262-1270.

6 Mueller-Pillasch F, Pohl B, Wilda M, et al. Expression of the highly conserved RNA binding protein KOC in embryogenesis. Mech Dev 1999;88:95-99.

7 Gress TM, Muller-Pillasch F, Geng M, et al. A pancreatic cancer-specific expression profile. Oncogene 1996;13:1819-1830.

8 Wang T, Hopkins D, Schmidt C, et al. Identification of genes differentially over-expressed in lung squamous cell carcinoma using combination of cDNA subtraction and microarray analysis. Oncogene 2000;19: 1519-1528.

9 Jiang Z, Chu P, Woda BA, et al. Analysis of RNAbinding protein IMP3 to predict metastasis and prognosis of renal-cell carcinoma: a retrospective study. Lancet Oncol 2006;7:556-564.

10 Munoz N, Bosch FX, Sanjose S, et al. Epidemiologic classification of human papillomavirus types associated with cervical cancer. N Engl J Med 2003; 348:518-527.

11 Milde-Langosch K, Schreiber C, Becker G, et al. Human papillomavirus a detection in cervical adenocarcinomas by polymerase chain reaction. Hum Pathol 1993;24:590-594.

12 Walboomers JMMM, Jacobs MV, Manos MM, et al. Human papillomavirus is a necessary cause of invasive cervical cancer worldwide. J Pathol 1999;189:12-19.

13 Brehm A, Kouzarides T. Retinoblastoma protein meets chromatin. Trends Biochem Sci 1999;24:142-145.

14 Mueller-Pillasch $\mathrm{F}$, Lacher U, Wallrapp $\mathrm{C}$, et al. Cloning of a gene highly overexpressed in cancer coding for a novel KH-domain containing protein. Oncogene 1997;14:2729-2733. 
15 Nielsen FC, Nielsen J, Christiansen J. A family of IGF-II mRNA binding proteins (IMP) involved in RNA trafficking. Scand J Clin Lab Invest 2001;234(Suppl):93-99.

16 Murrell A, Heeson S, Cooper WN, et al. An association between variants in the IGF2 gene and BeckwithWiedemann syndrome: interaction between genotype and epigenotype. Hum Mol Genet 2004;13:247-255.

17 Eggenschwiler J, Ludwig T, Fisher $\mathrm{P}$, et al. Mouse mutant embryos overexpressing IGF-II exhibit phenotypic features of the Beckwith-Wiedemann and Simpson-Golabi-Behmel syndromes. Genes Dev 1997;11:3128-3142.

18 Sun FL, Dean WL, Kelsey G, et al. Transactivation of Igf2 in a mouse model of Beckwith-Wiedemann syndrome. Nature 1997;389:809-815.
19 Zota V, Dresser K, Li C. Co-expression of KOC and p53 in uterine serous carcinoma. Mod Pathol 2006; 19(Suppl 3):106.

20 Milde-Langosch K, Schreiber C, Becker G, et al. Human papillomavirus: a detection in cervical adenocarcinomas by polymerase chain reaction. Hum Pathol 1993;24:590-594.

21 Negri G, Egarter-Vigl E, Kasal A, et al. p16 ${ }^{\mathrm{INK} 4 \mathrm{a}}$ is a useful marker for the diagnosis of adenocarcinoma of the cervix uteri and its precursors. Am J Surg Pathol 2003;27:187-193.

22 Riethdorf L, Riethdorf S, Lee KR, et al. Human papillomaviruses, expression of $\mathrm{p} 16^{\mathrm{INK} 4 \mathrm{a}}$, and early endocervical glandular neoplasia. Hum Pathol 2002; 33:899-904. 